\title{
Suffering-Centered Design
}

Bill Tomlinson

University of California, Irvine

Irvine, CA, 92697, USA

Victoria University of Wellington

Wellington, New Zealand

wmt@uci.edu

\begin{abstract}
Humans are skilled at closing their minds to the suffer-

ing of others. This paper argues that, over the past several decades, human computer interaction tools and techniques have both exacerbated and ameliorated this human tendency. It contributes a theoretical framework for thinking about the relationship between $\mathrm{HCl}$ and various forms of suffering, and a set of principles to support sufferingcentered design-design activities that foreground the suffering of others rather than obscure it. This paper proposes that there is a need for further exploration of ways that $\mathrm{HCl}$ can improve the collective human experience by supporting ways to open people's minds to the suffering of others.
\end{abstract}

\section{Author Keywords}

Suffering; Design; Wellbeing

\section{CCS Concepts}

-Human-centered computing $\rightarrow$ User centered design; Human computer interaction $(\mathrm{HCl})$; $\cdot$ Social and professional topics $\rightarrow$ Sustainability;

classroom use is granted without copies of all or part of this work for personal or for profit or commercial advantage and that copies bear this notice and the full citation on the first page. Copyrights for components of this work owned by others than the author(s) must be honored. Abstracting with credit is permitted. To copy otherwise, or republish, to post on servers or to redistribute to lists, requires prior specific

permission and/or a fee. Request permissions from permissions@acm.org. CHI '20 Extended Abstracts, April 25-30, 2020, Honolulu, HI, USA.

(C) 2020 Copyright is held by the owner/author(s). Publication rights licensed to ACM.

ACM ISBN 978-1-4503-6819-3/20/04 ...\$15.00.

http://dx.doi.org/10.1145/3334480.3381812

\section{Introduction}

In the coming decades, impacts from global climate change will be unevenly distributed around the world [16, 49]. In some countries and regions, dramatic shifts are already under way; in others, people may not experience direct effects 
for several decades. Nevertheless, as large parts of the world are profoundly impacted by environmental issues and the humanitarian crises they cause, people in less-affected areas will need to "get better at closing their minds to the suffering of others," as a colleague once put it.

People around the world are already very skilled at closing their minds to suffering. The vast disparities in lived experience between the very rich and the very poor, whether in the same city or across great distances, offer a demonstration of this phenomenon. While there are many actions being taken to alleviate various forms of suffering, from global humanitarian aid to sustainable fashion consumption [33], these actions are insufficient to prevent most suffering that currently exists around the world. The fact that a powerful human response to suffering is to ignore it, even when one has the wealth, time, and/or other resources to attend to it, is an important contributor to the interconnected global crises that span myriad human and non-human contexts (climate change, poverty, disease, racism, sexism, biodiversity loss, etc.).

Information technology is a powerful enabler of many human endeavors. And, as this paper later discusses, information technology is a powerful enabler of the human ability to close one's mind to the suffering of others. This paper explores how $\mathrm{HCl}$ in particular contributes to and pushes back against this process. In addition, it seeks to explore the potential for $\mathrm{HCl}$ and related fields to engage in suffering-centered design-design activities that foreground the suffering of others rather than obscure it. In doing so, this paper seeks to shift the focus of design from the individual using the system to other entities (people and non-human organisms) in the broader context of that user. By doing so, this paper seeks to help combat user- primacy, and support community-focused, future-focused, and biosphere-focused design efforts.

Suffering-centered design is deeply at odds with the current incarnation of industrial capitalism that dominates most work in computing. Software systems that foreground the suffering of others are likely to fail in the current industrial capitalist context. Rather than adopting suffering-centered systems, users will likely prefer systems that do not force them to confront the suffering created by the numerous institutions in which they are embedded and to some degree complicit. That doesn't mean that suffering-centered design is misguided, though. The fact that it is permissible, in industrial capitalism, to go about one's business while so many other people and other animals are killed or live in conditions of profound suffering, should be seen as an indictment of industrial capitalism itself. The sociotechnical systems that $\mathrm{HCl}$ researchers and practitioners build and deploy should not support willful ignorance of others' plight.

However, the prospect that there could be societal benefits resulting from foregrounding suffering does not mean that all people should be confronted by all forms of suffering at all times. Witnessing others' suffering could be harmful, for example, to individuals who have experienced trauma. Foregrounding suffering, but allowing individuals to opt out as needed, could help provide balance in these cases.

This paper contributes a novel theoretical framing of the relationships between suffering and $\mathrm{HCl}$ to the scholarly literature, as well as a set of design principles for sufferingcentered design. By collectively seeing a range of $\mathrm{HCl}$ tools and techniques as implicitly contributing to and combatting an existing human tendency; positioning this tendency and its support as coupled with deeply problematic social outcomes; and offering design directions that could help work against the tendency, this paper may be able to help 
the research and professional communities design more effectively across a range of domains. I hope this work will shift the conversation in $\mathrm{HCl}$ to make the suffering of others more salient in $\mathrm{HCl}$-enabled systems and services, even if aspects of this effort are at odds with much of the prevailing ethos of the civilizations in which $\mathrm{HCl}$ often operates.

\section{Related Work}

Many domains, from philosophy to design to religion (e.g., Buddhism) have engaged closely with suffering and related topics. A full description of work relating to suffering is beyond the scope of this work. In the human-computer interaction research domain specifically, scholars have explored how $\mathrm{HCl}$ can support compassion [47, 46, 68], mindfulness $[26,37]$, and wellbeing $[21,17]$. The research described here examines the inverse of many of these efforts, seeking to understand the implicit rather than explicit effects of $\mathrm{HCl}$ principles on users' relationships with others' suffering.

This work is perhaps most similar to prior work on empathy in $\mathrm{HCl}$. Whereas earlier work had encouraged empathy as an important part of designing for others, e.g. [94], more recent work [10] argues that the push toward helping designers empathize with the users they design for is problematic. This paper is distinct from this previous work in that it does not seek to help designers empathize with users, nor to help designers create systems that help users empathize with others, but rather to help designers create systems that help users see the suffering of others as a topic important to engage with.

As with [10], this paper seeks to "foreground... shared experiences". Empathy "risks obscuring [people's] complicity in the wider relations of power in which marginalisation, oppression and suffering occur" [62]. Here, I do not necessarily seek to help people empathize with others' suffering (although that certainly may occur); rather I seek to make suffering visible to those with social/cultural power, so that those potentially in a position to address that suffering are not insulated from it. Geographer Jared Diamond has proposed that the collapse of civilizations is often precipitated by the ruling class being insulated from the effects of their own actions [27]; I hope that by pushing back against this insulating tendency, the field of $\mathrm{HCl}$ may help to forestall profound civilizational challenges that many in the sustainability space see as increasingly likely (e.g., [57, 16, 79]).

The relationship between computing and various problematic psychological factors is an emerging area of interest in the $\mathrm{HCl}$ community. For example, in the 2015 Computing within Limits workshop, Knowles and Eriksson [44] grappled with a range of their own experiences working at the juncture of computing and sustainability such as guilt, anxiety, and worry. This paper is ideologically aligned with the work presented here-both engage with the suffering that work around the climate crisis and related themes brings. Here, I seek to build on Knowles and Eriksson's work and engage both with the suffering of the designers and users of technology, as well as of many other stakeholders in the users' present and future worlds.

In addition, a paper on asshole design [20] and a workshop at CHI 2019 titled CHI4EVIL engaged with an array of suffering-related topics. The workshop sought to "anticipate and reflect on the potential downsides of our technology design, research, and implementation" [74]. For example, Chan discussed how "excuses," in addition to villains and moral indifference, can bring about evil in the design process [18]. Another paper at this workshop described a different workshop with the goal of educating responsible technologists [35]. And Gibbs et al. mapped the seven deadly sins onto Facebook [34]. Together, this workshop's 
papers demonstrate that there are numerous instances in which $\mathrm{HCl}$ currently fails to grapple effectively with various forms of suffering and other societal concerns.

This work seeks to accomplish similar goals to the social justice [31], sustainability [6], HCl4D [19, 75], value sensitive design [32, 13], and responsible innovation [5] communities at $\mathrm{CHI}$. By seeking to foreground suffering, this work hopes to encourage people to act to prevent that suffering.

This paper's push back against the primacy of the user is also ideologically aligned with the negation of technology as described by Pierce's work on undesigning technology [66] as well as Baumer and Silberman's work questioning technology's appropriateness in various contexts [7]. While the work here focuses on a deep ideological shift in the focus of technology, rather than questioning its appropriateness altogether, I nevertheless see these works as offering similar critiques of the current modes of technological production.

The work described here also relates closely to research on uncomfortable interactions [9]. Suffering-centered design partially overlaps with uncomfortable interactions, in that many (but not all) suffering-centered designs may be uncomfortable for the user. Light et al. propose that design can support people in "paying attention to things that we do not wish to see and that make us uncomfortable" [50]. As [9] notes, many uncomfortable interactions deal with the suffering of others. However, suffering-centered design need not be uncomfortable for the user; in fact, sharing or addressing others' suffering can be a source of closeness, meaning, and other positive outcomes [52] for the sharer.

Much design theory focuses on helping the designer design for the user, for example via user-centered techniques such as the use of personas [69], or participatory design techniques such as participatory prototyping [12]. This pa- per seeks to move the focus from the user themself to other people and organisms, both at present and in the future.

More broadly, there have been substantial discussions in both research communities and the news media about whether technology is a dehumanizing force [71], or whether technology rather "is what makes us human" [64]. Ultimately, the relationship between technology and humanity is complex [59]; in this paper, rather than engaging with the question of whether technology in general is dehumanizing people broadly, I instead focus on the ways in which $\mathrm{HCl}$ in particular downplays or highlights one specific aspect of the human experience-the experience of suffering.

\section{Forms of Closing Minds to Others' Suffering}

This section documents four key forms of ignored suffering.

\section{Suffering of others in the present}

People look away from other people suffering right now around the world. Billions suffer from sexism, racism, homophobia, and many other forms of discrimination (e.g., [80]).

More than 700 million people live in poverty [87]. More than 300 million people live with depression [89]. There are tens of millions of climate migrants [40]. There are many millions living in oppressive regimes. All of these forms of suffering are well known, well documented, and longstanding. And yet millions of people ignore these forms of suffering in the people with whom they currently share the Earth.

\section{Suffering of others in the future}

People also ignore the suffering of future people. While many in industrialized nations aspire to building civilizations that are more tolerant, welcoming, egalitarian, and supportive, many of the problems that exist in the present are likely to get worse in the future, and few are likely to be extinguished altogether. The World Bank projects that there could be more than 140 million climate migrants by 
2050 [86]. The homeless population aged 65 and over is increasing rapidly [22]. Depression is on the rise [88]. Rising income inequality is potentially implicated in a wide range of social ills [43]. And yet, millions of people, through their actions, their votes, and their opinions, demonstrate that they have closed their minds to this future suffering.

\section{Suffering of future self}

People look away from their future selves, too, making short-sighted decisions in many domains [15]. Humans routinely act in ways that discount their own futures, a phenomenon known as temporal myopia [93]. While the delaying of gratification is a well-studied human ability, ignoring one's own future suffering may be an adaptive decision. As recent work debunking the famous Stanford Marshmallow Test shows [84], it may not be a lack of willpower that leads to decisions favoring the present; rather, that "daily life holds fewer guarantees" [3] for poorer children than for more affluent ones. Nevertheless, people often act in ways that contribute to their own future suffering.

\section{Suffering of animals in the present and future}

Finally, people look away from the suffering of animals around the world. The capacity of numerous animal species to suffer is well-documented [24]. Nevertheless, billions of humans eat animals, supporting an industry that kills hundreds of millions of animals capable of suffering every year [81], and causing hundreds of millions of others to endure appalling living conditions [91]. Furthermore, humans have created social systems that lead to the abandonment of millions of pets each year [2]. More broadly, populations of vertebrate animals around the world have fallen by $60 \%$ in the past 50 years, representing millions of instances of animal suffering [90]. And looking forward, humans are continuing to drive hundreds of species (at least) extinct every year through our collective actions and inactions [92]. Hu- mans routinely behave in ways that ignore animal suffering, both now and in the future.

\section{Rationale}

There are numerous reasons why people turn away from suffering, some of which are good reasons. Milgram has argued that people learn to ignore the suffering of others because it is psychologically overwhelming to do otherwise [56]. People may feel powerless to enact meaningful change, or may not expect to live long enough for it to matter, or may not adhere to a value system that places significant value on certain kinds of suffering (non-human animals). People may see value in suffering [73]. People may be doing their best just to hold their own lives together in the present. Nevertheless, despite the validity of (some) reasons for it, humans routinely ignore others' suffering.

\section{$\mathrm{HCl}$ Support for Closing Minds to Suffering}

While humans have a long history of closing their minds to the suffering of others, modern $\mathrm{HCl}$ systems provide significant support for the effort. Here I document five key mechanisms through which $\mathrm{HCl}$ does so.

Separating people from each other and from the world The rise of networked communication such as email, instant messaging, and video conferencing closes off many contextual cues to suffering that would otherwise be apparent in face-to-face communication. In face-to-face communication, people experience many aspects of their social partnerstheir demeanor, their tone of voice, etc. If a communication partner is suffering, their suffering is often apparent; mirror neurons in the brain [38] enable emotional contagion. Without those cues, users of networked communication systems have an easier time dehumanizing social partners. Many $\mathrm{HCl}$ researchers are working to broaden the emotional spectrum available via these media, e.g., [14, 36]; 
however, communications media still substantially reduce the possibility of witnessing suffering.

Online commerce contributes to this phenomenon as well. Amazon's one day delivery helps purchasers ignore the fact that products are frequently made across the world under deplorable working conditions, contributing to the invisibility of workers' suffering. Numerous design decisions made in the development of the sociotechnical systems involved in those objects' arrival at customers' doors work to obscure the processes by which they are manufactured and delivered. While this is true of many aspects of the sale of consumer goods across human history, the user interaction paradigms for Amazon and many other online retailers vigorously reinforce this obfuscation.

Even systems that actively seek to connect people to each other end up enforcing separation. Social media filters whose experiences a person gets to share, often resulting in social homogenization [53]. As a consequence, many forms of suffering are not present on a person's friends list or news feed. The digital divide, in which a subset of (usually poor) people do not have access to the World Wide Web and various systems on it, may prevent certain forms of suffering from being present on the internet.

Also, the culture of social media is typically one in which people self-filter with a bias for positive posts [54], thus creating social pressure to conform to mostly-positive posts.

This self-curation contributes to the underrepresentation of explicit suffering on social media. While people may try to filter their self-presentation in non-computational contexts as well, contextual cues often make their suffering known to their social partners.

In addition, community standards established by various platforms may also help ensure that certain kinds of suf- fering are not displayed on social media. For example, Facebook has banned PETA images of animal suffering [45]. While Facebook is likely correctly intuiting that graphic images of violence against animals is bad for business, it nevertheless contributes to the sanitization of suffering on social media.

\section{Fostering attention scarcity}

$\mathrm{HCl}$ also contributes to closing people's minds to the suffering of others by fostering scarcity in people's attention. As an example, design principles such as the use of shortcuts, the goal of yielding closure, and the reduction of shortterm memory load [85] all serve to increase the already rapid churn of topics to focus on. Given the scarce resource of human attention in the zero-sum game of the attention economy, this makes it harder to attend to many other phenomena, including the suffering of others.

This attention scarcity is an issue with much of industrial capitalism [67]; the rapid cycling of consumer products from manufacturing to (brief) usage to waste is pervasive around the industrialized world. Coupled with "bovine design" [50]—design that makes people placid and docilemany $\mathrm{HCl}$ principles represent a distillation of this way of being into a computational design discipline.

\section{Supporting user primacy}

A related way that $\mathrm{HCl}$ implicitly encourages people to ignore others' suffering is by supporting the primacy of "the user". User-centered design is only user-centered from the designer's point of view; from the point of view of the user, it is self-centered, and therefore not focused on others. In addition, the emphasis on rapid satisfaction of human desires (or at least the desires of humans who are materially wealthy), which is everpresent in many different $\mathrm{HCl}$-heavy computational systems designed for seamless and speedy interaction, helps perpetuate a self-focused way of living. 
Enabling abstraction

Suffering is concrete, personal, and context rich. The field of computing, however, frequently seeks abstraction, strives for impersonality, and has difficulty with context. By enabling abstraction-preventing us from seeing the suffering of an Amazon delivery driver having to urinate in a bottle because there's no time for a break [65], or of the child laborer who manufactured an iPhone [95], or of the gorilla eaten by the workers mining coltan to go into that iPhone [76]—platforms like Amazon and Apple insulate the wealthy from the effects of their actions. As mentioned earlier, this insulation of the ruling class may set the stage for civilizational collapse. Abstraction, while desirable as a design principle for software engineering, and effective as a strategy for hiding harmful effects of various products and services, simultaneously enables people to close their minds to the suffering of others.

Contributing to growth

Finally, modern $\mathrm{HCl}$ is heavily implicated in the growthbased paradigm that is so prevalent in the industrialized world [57]. By aligning and integrating well within that paradigm, $\mathrm{HCl}$ is also, in part, responsible for it. The last several decades of growth have created great value for a few individuals while leaving many others behind [48]. The world's richest human, Jeff Bezos, made his money in large part through innovative computational approaches to business, including many innovations in $\mathrm{HCl}$. Runaway consumerism has caused suffering of non-human animals both directly, via the sale of animal products, and indirectly, mediated through the carbon emissions and ensuing climate change that economic growth has caused [1]. $\mathrm{HCl}$ is guilty by association, even if it is "just following orders" from captains of industry to make products and services that will sell well.

\section{$\mathrm{HCl}$ Support for Opening Minds to Suffering \\ While the previous section has documented a variety of} ways in which $\mathrm{HCl}$ obscures the suffering of others, $\mathrm{HCl}$ has also been involved in social changes that have helped users become aware of the suffering of others. This section documents several mechanisms by which this happens.

\section{Increasing social connectivity}

The past few decades have witnessed an increase in the ability of people around the world to experience diverse phenomena occurring in the lives of people and non-human animals elsewhere in the world. While $\mathrm{HCl}$ is not solely responsible for this phenomenon-networking software /hardware and broader civilization-scale trends such as globalization have also been instrumental- $\mathrm{HCl}$ has nevertheless played a key role in the rise of many forms of computermediated communication. Therefore, $\mathrm{HCl}$ has been instrumental in making available the suffering of distant others.

In addition to enabling flows of information, the field of $\mathrm{HCl}$ and the computational systems it has enabled have also helped people take action to ameliorate others' suffering. Contrasted with a more constrained, strictly oneway, medium such as television, modern $\mathrm{HCl}$-enabled, net worked communication brings about numerous opportunities for solidarity, accountability, and activism.

\section{Engaging across diverse communities}

While increasing the diversity of people with whom one communicates does not inherently increase the access of any particular user to more suffering than access to a more homogeneous group would, it nevertheless does increase the likelihood of encountering suffering of a kind that is unfamiliar to the user. And this engagement with unfamiliar suffering-moving beyond one's parochial sphere of familiarity to a potentially much broader sphere of influenceis critical to addressing many global-scale crises. This is 
particularly relevant for privileged members of wealthy, technologically-enabled communities, who may easily have the option to remain in an information bubble, insulated from people different from themselves. Previous work on postcolonial computing [41] has explored the particular role of $\mathrm{HCl}$ in globalization, and has shifted the research community's discussion of cultural power dynamics, focusing on "engagement, articulation, and translation" across cultures. By supporting efforts to engage people with diverse communities, $\mathrm{HCl}$ contributes to people experiencing a diverse array of forms of suffering as well.

Critically engaging with techno-utopianism/techno-solutionism While computation is sometimes positioned as the solution to many of the world's problems, $\mathrm{HCl}$ as a field is relatively nuanced in its engagement with this domain. The technoutopianism/techno-solutionism that is quite present but not always well-interrogated in Silicon Valley and many computing subfields is often examined with a more critical eye in $\mathrm{HCl}[4,51]$. Understanding suffering as a complex, contextrich phenomenon, rather than as a problem that can be "engineered away", is a strength of $\mathrm{HCl}$.

Taken together, these mechanisms demonstrate that $\mathrm{HCl}$ has played a significant force in enabling potentially billions of people to become aware of the suffering of others. ${ }^{1}$

\section{Design Principles for Suffering-Centered Design}

This section proposes a set of design principles that can work against the human tendency to ignore others' suffering. These goals build on a tradition in design of engaging with the "social and moral responsibilities of design" [61]. The goal of these principles is twofold: first, to help people

${ }^{1}$ It is also worth noting that making the suffering of others more available to others may play into existing problematic individual and societal tendencies, such as voyeurism and digital "slum tourism" [8]. experience the suffering of others, and second, to position them to help alleviate it. While the experience of witnessing suffering is frequently undesirable, it is typically less severe than enduring the suffering itself. To improve the collec-

tive wellbeing of humanity in the long term, individuals may need to experience more of the suffering that surrounds them in the world at present and that is likely in the future.

Broaden social contact

It is unlikely that individuals or groups will accidentally take action to alleviate suffering that they do not know about.

Therefore, to help people engage with suffering, it would be useful to broaden the social contact that people have, in order to allow them to interact with those suffering. For example, rather than allowing people to self-select their entire friends-list, a social media platform could facilitate the forming of friendships between individuals whose lived experiences would broaden both individuals' exposure to other people in the world. One could imagine using network theory [83] to determine how many connections of what kinds between various networks would be needed to create a certain level and consistency of exposure to suffering.

You might say, wait, our users want to have control of their friends list! But designers are not obligated to give users exactly what they want. Designers build systems that make users change their passwords, even when they don't want to. Designers show people ads they (often) don't want. Broadening social contact may be in the long-term best interests of users, even if in the short term they would prefer more narrow social circles. Nevertheless, this example highlights the tensions that may arise between various stakeholders-designers, users, and others effected by a system's use-in efforts to enact suffering-centered design. 
Welcome suffering

Right now, in much of industrial civilization, suffering is pathologized [72]. Lack of wellbeing is often experienced as a weakness or shortcoming that should be hidden from public view. Designers have a great deal of power to shape how civilizations operate. Designers and others have created and studied communities that support people that are suffering from cancer [82], that identify individuals who may be suffering from suicidal ideation [25], or to find online support for grief [55]. Designs that make suffering more welcome across a range of different domains, from personal informatics to user modeling to augmented reality, could help to address the difficult issue of suffering more broadly. Platforms such as the Toastme subreddit [70] already do so to a degree, providing a community that welcomes individuals who are suffering and in need of kind words.

Consider the long term

Many designs that implicitly or explicitly work to mask or downplay suffering do so because they are focused on short-term phenomena such as repeat viewers or quarterly profit. However, short-term success is sometimes at odds with long-term flourishing. Recognizing that a society that ignores suffering in the short term may well be one where more people will ultimately end up experiencing suffering, designers could frame the opening of users' eyes to suffering as a long-term strategy for collective wellbeing. Longterm thinking can help people interacting with sociotechnical systems focus on topics other than their present selves, attending to people and other organisms in the future (potentially including themselves).

The prospect of long-term thinking, with regard to suffering, is well aligned with long-term thinking from a sustainability perspective. In particular, Lisa Nathan and her colleagues' work on multi-lifespan design in the context of the United
Nations International Criminal Tribunal for Rwanda [58] aligns well here. Eli Blevis' concept of heirloom technologies [11] is similarly aligned, encouraging connection with people who have used technological objects previously (rather than hiding them from view), and as such could make their experiences-both joys and suffering-more accessible to the current user.

Nevertheless, when presented with information in a certain way, people may be able to make longer-term decisions than they otherwise might. For example, research suggests that showing people an age-morphed picture of themselves can get them to contribute more to their retirement [29]). There are efforts in $\mathrm{HCl}$ to extend time horizons, such as slow technology [60] and extended human-centered computing [78]. And social movements such as \#DontLookAway are seeking to keep focus on suffering happening in the world right now, in particular the concentration camps that exist with the US. But currently, the way Twitter operates will likely ensure that it is not trending for long.

\section{Encourage perspective-taking}

Another principle that designers may follow to support suffering-centered design is to encourage perspectivetaking. Perspective-taking is a well-studied psychological phenomenon in various contexts, such as child development [30] and multicultural literacy [77]. Encouraging people to take the perspective of others can help to foreground suffering that those others may be experiencing. Many games focus on role-playing as other characters; some games, such as Darfur is Dying [39], provide players with a window into particular kinds of suffering being endured by others. It's worth noting that efforts to enable perspectivetaking may entail an array of risks, such as causing people to believe, incorrectly, that they understand a certain context better than they actually do. 
Oppose growth

As a final design principle, $\mathrm{HCl}$ researchers and practitioners can work to oppose economic growth, or at least economic growth that leads to suffering for humans and nonhuman animals (in which current economic growth is heavily implicated). While it may seem like opposing economic growth is beyond the scope of $\mathrm{HCl}$, and fits more squarely in the purview of economists or politicians, there are existing models from other computing disciplines where related activities are already unfolding. For example, in software engineering, sustainability is being put forward as an important non-functional requirement, in the same league as safety and security. [63] While sustainability may seem less dramatic than opposing economic growth, and sustainability is already a well-explored domain in $\mathrm{HCl}[11,28]$, there is substantial research suggesting that supporting a steadystate economy [23] or even working toward degrowth [42] could be important aspects of a sustainable future. Therefore, if $\mathrm{HCl}$ sees itself as being able to contribute toward sustainability, it may also need to engage with these potential economic directions. The Computing within Limits community [57] is already moving in these directions, and provides a range of initial forays into how computing can engage with these issues.

Taken together, these design principles could help lead to technologies that build stronger and more diverse communities, and make room in those communities for a broader array of human experiences. These technologies would focus on long-term wellbeing, and wellbeing broadly defined, where one individual's wellbeing is in part a function of the wellbeing of others. And they would recognize that humans live on a finite planet, in which the overexploitation of resources by some individuals is increasingly likely to harm others.

\section{Conclusion}

This paper began with the assertion that climate change is causing suffering for billions of humans and other animals, and that this suffering will grow worse as the climate crisis escalates. As a result, wealthy individuals well-positioned in industrial capitalist societies, who may not feel the immediate effects of climate change, will likely address these growing problems primarily by closing their minds to the suffering of others. It positioned information technology in general, and $\mathrm{HCl}$ in particular, as often supportive of this problematic tendency. And it offered a set of design principles to enable suffering-centered design, despite an acknowledgment that suffering-centered design would likely be at odds with norms of current industrial capitalist societies.

I do not propose that suffering-centered design is "a winner", as design strategies go. If one works for a major corporation seeking to maximize shareholder wealth, or as a researcher who seeks to enable the status quo of life for already-wealthy humans, suffering-centered design is vexed. However, rather than seeing this approach as an inconvenience at odds with key incentive structures for many design activities, I see it as a way to highlight a sickness in the civilization in which most $\mathrm{HCl}$ researchers and practitioners live. If the $\mathrm{HCl}$ field has any power to enact change, it should seek to do so in this domain. Allowing billions of people and billions of other animals, now and in the future, to suffer so severely at the hands of the satisfaction of the material desires of a relatively few wealthy humans is, in a word, inhumane. We should be ashamed to be contributing to this system.

\section{Acknowledgments}

The author thanks Neil Young, Rebecca W. Black, Barath Raghavan, and Khushi Valia for their contributions. 


\section{REFERENCES}

[1] Alex O. Acheampong. 2018. Economic growth, CO2 emissions and energy consumption: What causes what and where? Energy Economics 74 (2018), 677 692. DOI : http://dx.doi.org/https:

//doi.org/10.1016/j.eneco.2018.07.022

[2] ASPCA. 2019. Pet Statistics | Shelter Intake and Surrender | ASPCA. (2019).

https: //www . aspca.org/animal-homelessness/ shelter-intake-and-surrender/pet-statistics Accessed: 2019-08-09.

[3] The Atlantic. 2018. Why Rich Kids Are So Good at the Marshmallow Test. (2018).

https://www. theatlantic.com/family/archive/ 2018/06/marshmallow-test/561779/ Accessed: 2019-08-09.

[4] Shaowen Bardzell. 2018. Utopias of Participation: Feminism, Design, and the Futures. ACM Trans. Comput.-Hum. Interact. 25, 1, Article 6 (Feb. 2018), 24 pages. DOI:http://dx.doi.org/10.1145/3127359

[5] Oliver Bates, Kathy New, Samantha Mitchell-Finnigan, Matthew Louis Mauriello, Christian Remy, Roy Bendor, Samuel Mann, Simran Chopra, Adrian K. Clear, and Chris Preist. 2019. Towards a Responsible Innovation Agenda for $\mathrm{HCl}$. In Extended Abstracts of the 2019 CHI Conference on Human Factors in Computing Systems (CHI EA '19). Association for Computing Machinery, New York, NY, USA, Article Paper W24, 8 pages. DOI :

http://dx.doi.org/10.1145/3290607.3299017

[6] Oliver Bates, Vanessa Thomas, Christian Remy, Lisa P. Nathan, Samuel Mann, and Adrian Friday.
2018. The Future of $\mathrm{HCl}$ and Sustainability:

Championing Environmental and Social Justice.. In Extended Abstracts of the $2018 \mathrm{CHI}$ Conference on Human Factors in Computing Systems (CHI EA '18). Association for Computing Machinery, New York, NY, USA, Article Paper SIG01, 4 pages. DOI : http://dx.doi.org/10.1145/3170427.3185365

[7] Eric P.S. Baumer and M. Six Silberman. 2011. When the Implication is Not to Design (Technology). In Proceedings of the SIGCHI Conference on Human Factors in Computing Systems (CHI '11). ACM, New York, NY, USA, 2271-2274. DOI :

http://dx.doi.org/10.1145/1978942.1979275

[8] Christine Bednarz. 2018. Inside the Controversial World of Slum Tourism. (2018).

https://www. nationalgeographic.com/travel/ features/photography/history-controversydebate-slum-tourism/

[9] Steve Benford, Chris Greenhalgh, Gabriella Giannachi, Brendan Walker, Joe Marshall, and Tom Rodden. 2012. Uncomfortable Interactions. In Proceedings of the SIGCHI Conference on Human Factors in Computing Systems (CHI '12). ACM, New York, NY, USA, 2005-2014. DOI : http://dx.doi.org/10.1145/2207676.2208347

[10] Cynthia L. Bennett and Daniela K. Rosner. 2019. The Promise of Empathy: Design, Disability, and Knowing the "Other". In Proceedings of the $2019 \mathrm{CHI}$

Conference on Human Factors in Computing Systems (CHI '19). ACM, New York, NY, USA, Article 298, 13 pages. DOI :

http://dx.doi.org/10.1145/3290605.3300528 
[11] Eli Blevis. 2007. Sustainable Interaction Design: Invention \& Disposal, Renewal \& Reuse. In Proceedings of the SIGCHI Conference on Human Factors in Computing Systems (CHI '07). ACM, New York, NY, USA, 503-512. DOI : http://dx.doi.org/10.1145/1240624.1240705

[12] Johan Blomkvist, Stefan Holmlid, Fredrik Sandberg, and Bo Westerlund. 2012. Workshop: Exploring Participatory Prototyping of Services. In Proceedings of the 12th Participatory Design Conference: Exploratory Papers, Workshop Descriptions, Industry Cases - Volume 2 (PDC '12). ACM, New York, NY, USA, 151-152. DOI :

http://dx.doi.org/10.1145/2348144.2348195

[13] Alan Borning and Michael Muller. 2012. Next Steps for Value Sensitive Design. In Proceedings of the SIGCHI Conference on Human Factors in Computing Systems (CHI '12). Association for Computing Machinery, New York, NY, USA, 1125-1134. DOI : http://dx.doi.org/10.1145/2207676.2208560

[14] Yulia Brazauskayte. 2019. Bodily Connectedness: Designing Affective, Movement-based Communication Media. In Extended Abstracts of the $2019 \mathrm{CHI}$ Conference on Human Factors in Computing Systems (CHI EA '19). ACM, New York, NY, USA, Article DC03, 6 pages. DOI:

http://dx.doi.org/10.1145/3290607.3299074

[15] Dean Buonomano. 2012. Temporal Myopia: Making Bad Long-term Decisions.

https://www. psychologytoday . com/us/blog/brainbugs/201209/temporal-myopia-making-bad-longterm-decisions. (2012). Accessed: 2019-08-07.
[16] Marshall Burke, Solomon M. Hsiang, and Edward Miguel. 2015. Global non-linear effect of temperature on economic production. Nature 527, 7577 (nov 2015), 235-239. DOI :

http://dx.doi.org/10.1038/nature15725

[17] Rafael A. Calvo and Dorian Peters. 2014. Positive Computing: Technology for Well-Being and Human Potential. The MIT Press.

[18] Jeff Chan. 2019. Akrasia: Justifying Evil and the Study of Excuses. In Workshop on CHI4EVIL, 2019 CHI Conference on Human Factors in Computing Systems.

[19] Marshini Chetty and Rebecca E. Grinter. 2007. HCl4D: Hci Challenges in the Global South. In $\mathrm{CHI}$ ' 07 Extended Abstracts on Human Factors in Computing Systems (CHI EA '07). Association for Computing Machinery, New York, NY, USA, 2327-2332. DOI : http://dx.doi.org/10.1145/1240866.1241002

[20] Shruthi Sai Chivukula, Chris Watkins, Lucca McKay, and Colin M. Gray. 2019. "Nothing Comes Before Profit": Asshole Design In the Wild. In Extended Abstracts of the $2019 \mathrm{CHI}$ Conference on Human Factors in Computing Systems (CHI EA âÁŹ19). Association for Computing Machinery, New York, NY, USA, Article Paper LBW1314, 6 pages. DOI : http://dx.doi.org/10.1145/3290607.3312863

[21] David Coyle, Conor Linehan, Karen Tang, and Sian Lindley. 2012. Interaction Design and Emotional Wellbeing. In $\mathrm{CHI}$ '12 Extended Abstracts on Human Factors in Computing Systems (CHI EA '12). ACM, New York, NY, USA, 2775-2778. DOI :

http://dx.doi.org/10.1145/2212776.2212718 
[22] Dennis Culhane, Dan Treglia, Thomas Byrne, Stephen Metraux, Randall Kuhn, Kelly Doran, Eileen Johns, and Mpa Maryanne Schretzman. The Emerging Crisis of Aged Homelessness: Could Housing Solutions Be Funded by Avoidance of Excess Shelter, Hospital, and Nursing Home Costs? Technical Report.

https://www.aisp. upenn.edu/wpcontent/uploads/2019/01/Emerging-Crisis- of Aged-Homelessness-1.pdf

[23] Herman E. Daly. 1993. Steady-State Economics: A New Paradigm. New Literary History 24, 4 (1993), 811-816. http://www.jstor.org/stable/469394

[24] Marian Stamp Dawkins. 1980. Animal suffering : the science of animal welfare. Chapman and Hall. 149 pages. https://books.google.co.nz/books?hl=en

[25] Munmun De Choudhury, Emre Kiciman, Mark Dredze, Glen Coppersmith, and Mrinal Kumar. 2016.

Discovering Shifts to Suicidal Ideation from Mental Health Content in Social Media. In Proceedings of the 2016 CHI Conference on Human Factors in Computing Systems (CHI '16). ACM, New York, NY, USA, 2098-2110. DOI:

http://dx.doi.org/10.1145/2858036.2858207

[26] Katie Derthick. 2014. Understanding Meditation and Technology Use. In CHI '14 Extended Abstracts on Human Factors in Computing Systems (CHI EA '14). ACM, New York, NY, USA, 2275-2280. DOI : http: //dx.doi.org/10.1145/2559206.2581368

[27] Jared M. Diamond. 2005. Collapse: how societies choose to fail or succeed. Penguin Books.

[28] Carl DiSalvo, Phoebe Sengers, and Hrönn Brynjarsdóttir. 2010. Mapping the Landscape of Sustainable $\mathrm{HCl}$. In Proceedings of the SIGCHI
Conference on Human Factors in Computing Systems (CHI '10). ACM, New York, NY, USA, 1975-1984.

DOI:http://dx.doi.org/10.1145/1753326.1753625

[29] H. Ersner-Hershfield, J.N. Bailenson, and L.L. Carstensen. 2008. Feeling more connected to your future self: Using immersive virtual reality to increase retirement saving. (2008). https:

//vhil.stanford.edu/pubs/2008/feeling-moreconnected-to-your-future-self-using-immersivevirtual-reality-to-increase-retirement-saving/ Accessed: 2019-09-16.

[30] Brad M. Farrant, Tara A. J. Devine, Murray T. Maybery, and Janet Fletcher. 2012. Empathy, Perspective Taking and Prosocial Behaviour: The Importance of Parenting Practices. Infant and Child Development 21, 2 (2012), 175-188. DOI : http://dx.doi.org/10.1002/icd. 740

[31] Sarah Fox, Mariam Asad, Katherine Lo, Jill P. Dimond, Lynn S. Dombrowski, and Shaowen Bardzell. 2016.

Exploring Social Justice, Design, and $\mathrm{HCl}$. In Proceedings of the $2016 \mathrm{CHI}$ Conference Extended Abstracts on Human Factors in Computing Systems (CHI EA '16). Association for Computing Machinery, New York, NY, USA, 3293âĂŞ3300. DOI : http://dx.doi.org/10.1145/2851581.2856465

[32] Batya Friedman. 1996. Value-Sensitive Design. Interactions 3, 6 (Dec. 1996), 16âĂŞ23. DOI : http://dx.doi.org/10.1145/242485.242493

[33] Sonja Maria Geiger and Johannes Keller. 2018. Shopping for Clothes and Sensitivity to the Suffering of Others: The Role of Compassion and Values in Sustainable Fashion Consumption. Environment and Behavior 50, 10 (2018), 1119-1144. DOI : http://dx.doi.org/10.1177/0013916517732109 
[34] Pamela Gibbs, Gloria Opoku-Boateng, and Siobahn Day. 2019. Seven Deadly Sins: A Case Study on Facebook. In Workshop on CHI4EVIL, 2019 CHI Conference on Human Factors in Computing Systems.

[35] Erhardt Graeff. 2019. Fostering the Good, Responsible Technologist to Face any Dilemma. In Workshop on CHI4EVIL, 2019 CHI Conference on Human Factors in Computing Systems.

[36] Mariam Hassib, Max Pfeiffer, Stefan Schneegass, Michael Rohs, and Florian Alt. 2017. Emotion Actuator: Embodied Emotional Feedback Through Electroencephalography and Electrical Muscle Stimulation. In Proceedings of the $2017 \mathrm{CHI}$ Conference on Human Factors in Computing Systems (CHI '17). ACM, New York, NY, USA, 6133-6146. DOI : http://dx.doi.org/10.1145/3025453.3025953

[37] Mahmoud Mohamed Hussien Ahmed, Chaklam Silpasuwanchai, Kavous Salehzadeh Niksirat, and Xiangshi Ren. 2017. Understanding the Role of Human Senses in Interactive Meditation. In Proceedings of the $2017 \mathrm{CHI}$ Conference on Human Factors in Computing Systems (CHI '17). ACM, New York, NY, USA, 4960-4965. DOI : http://dx.doi.org/10.1145/3025453.3026000

[38] Marco lacoboni. 2009. Imitation, Empathy, and Mirror Neurons. Annual Review of Psychology 60, 1 (2009), 653-670. DOI : http://dx.doi.org/10.1146/annurev. psych.60.110707.163604 PMID: 18793090.

[39] interFUEL, LLC. 2006. Darfur is Dying. (2006). http: //www.gamesforchange.org/game/darfur-is-dying/ Accessed: 2019-12-31.
[40] Dina lonesco. 2019. Let's Talk About Climate Migrants, Not Climate Refugees - United Nations Sustainable Development. (2019). https://www. un.org/ sustainabledevelopment/blog/2019/06/lets-talkabout-climate-migrants-not-climate-refugees/ Accessed: 2019-08-09.

[41] Lilly Irani, Janet Vertesi, Paul Dourish, Kavita Philip, and Rebecca E. Grinter. 2010. Postcolonial Computing: A Lens on Design and Development. In Proceedings of the SIGCHI Conference on Human Factors in Computing Systems (CHI '10). ACM, New York, NY, USA, 1311-1320. DOI : http://dx.doi.org/10.1145/1753326.1753522

[42] Giorgos Kallis. 2011. In defence of degrowth. Ecological Economics 70, 5 (2011), 873 - 880. DOI : http:

//dx.doi.org/10.1016/j.ecolecon.2010.12.007

[43] Brian Keeley. 2015. How does income inequality affect our lives? Technical Report. 63-77 pages. DOI : http://dx.doi.org/10.1787/9789264246010-6-en

[44] Bran Knowles and Elina Eriksson. 2015. Deviant and guilt-ridden: Computing within psychological limits. First Monday 20, 8 (2015). DOI : http://dx.doi.org/10.5210/fm.v20i8.6127

[45] Michelle Kretzer. 2016. Facebook Banned PETA's Picture-But You Can Still See It Here | PETA. (2016). https://www. peta.org/blog/facebook-bannedpetas-picture-but-can-still-see/ Accessed: 2019-08-09. 
[46] Minha Lee, Sander Ackermans, Nena van As, Hanwen Chang, Enzo Lucas, and Wijnand IJsselsteijn. 2019a. Caring for Vincent: A Chatbot for Self-Compassion. In Proceedings of the $2019 \mathrm{CHI}$ Conference on Human Factors in Computing Systems (CHI '19). ACM, New York, NY, USA, Article 702, 13 pages. DOI :

http://dx.doi.org/10.1145/3290605.3300932

[47] Minha Lee, Lily Frank, and Wijnand ljsselsteijn. 2019b. Exploring Compassion through $\mathrm{HCl}$. Workshop on Exploring the Intersection of Philosophy and $\mathrm{HCl}, \mathrm{CHI}$ '19 (2019).

[48] David Leonhardt. 2017. Our Broken Economy, in One Simple Chart. (2017).

https://www.nytimes.com/interactive/2017/08/07/ opinion/leonhardt-income-inequality.html Accessed: 2019-08-09.

[49] Corey Lesk, Pedram Rowhani, and Navin Ramankutty. 2016. Influence of extreme weather disasters on global crop production. Nature 529 (Jan 2016), 84. https://doi.org/10.1038/nature16467http: //10.0.4.14/nature16467https:

//www.nature.com/articles/nature16467

[50] Ann Light, Alison Powell, and Irina Shklovski. 2017. Design for Existential Crisis in the Anthropocene Age. In Proceedings of the 8th International Conference on Communities and Technologies. Association for Computing Machinery, New York, NY, USA, 270-279. DOI : http://dx.doi.org/10.1145/3083671.3083688

[51] Silvia Lindtner, Shaowen Bardzell, and Jeffrey Bardzell. 2016. Reconstituting the Utopian Vision of Making: $\mathrm{HCl}$ After Technosolutionism. In Proceedings of the $2016 \mathrm{CHI}$ Conference on Human Factors in Computing Systems (CHI '16). ACM, New York, NY,
USA, 1390-1402. DOI:

http://dx.doi.org/10.1145/2858036.2858506

[52] Tim Lomas. 2015. Self-transcendence through shared suffering: An intersubjective theory of compassion. (2015).

[53] Jan-Erik Lonnqvist and Juha V.A. Itkonen. 2016 Homogeneity of personal values and personality traits in Facebook social networks. Journal of Research in Personality 60 (2016), 24 - 35. DOI :

http://dx.doi.org/10.1016/j.jrp.2015.11.001

[54] Katerina Lup, Leora Trub, and Lisa Rosenthal. 2015. Instagram \#Instasad?: Exploring Associations Among Instagram Use, Depressive Symptoms, Negative Social Comparison, and Strangers Followed.

Cyberpsychology, Behavior, and Social Networking 18, 5 (2015), 247-252. DOI :

http://dx.doi.org/10.1089/cyber.2014.0560 PMID: 25965859

[55] Michael Massimi. 2013. Exploring Remembrance and Social Support Behavior in an Online Bereavement Support Group. In Proceedings of the 2013 Conference on Computer Supported Cooperative Work (CSCW '13). ACM, New York, NY, USA, 1169-1180. DOI : http://dx.doi.org/10.1145/2441776.2441908

[56] Stanley Milgram. 1970. The Experience of Living in Cities. Science 167, 3924 (1970), 1461-1468. http://www.jstor.org/stable/1728966

[57] Bonnie Nardi, Bill Tomlinson, Donald J. Patterson, Jay Chen, Daniel Pargman, Barath Raghavan, and Birgit Penzenstadler. 2018. Computing Within Limits. Commun. ACM 61, 10 (Sept. 2018), 86-93. DOI : http://dx.doi.org/10.1145/3183582 
[58] Lisa P. Nathan, Milli Lake, Nell Carden Grey, Trond Nilsen, Robert F. Utter, Elizabeth J. Utter, Mark Ring, Zoe Kahn, and Batya Friedman. 2011. Multi-lifespan Information System Design: Investigating a New Design Approach in Rwanda. In Proceedings of the 2011 iConference (iConference '11). ACM, New York, NY, USA, 591-597. DOI :

http://dx.doi.org/10.1145/1940761.1940841

[59] David E. Nye. 2006. Technology matters: questions to live with. MIT Press.

[60] William Odom, Richard Banks, Abigail Durrant, David Kirk, and James Pierce. 2012. Slow Technology: Critical Reflection and Future Directions. In Proceedings of the Designing Interactive Systems Conference (DIS '12). ACM, New York, NY, USA, 816-817. DOI :

http://dx.doi.org/10.1145/2317956.2318088

[61] Victor Papanek. 1985. Design for the Real World: Human Ecology and Social Change. Academy Chicago.

[62] Carolyn Pedwell. 2014. Affective relations: The transnational politics of empathy. Springer.

[63] B. Penzenstadler, A. Raturi, D. Richardson, and B. Tomlinson. 2014. Safety, Security, Now Sustainability: The Nonfunctional Requirement for the 21st Century. IEEE Software 31, 3 (May 2014), 40-47. DOI : http://dx.doi.org/10.1109/MS.2014.22

[64] Andrea Peterson. 2013. Technology is not dehumanizing. It's what makes us human. - The Washington Post. (October 2013).

https://www . washingtonpost. com/news/theswitch/wp/2013/10/17/technology-is-not- dehumanizing-its-what-makes-us-human/ Accessed: 2019-08-09.

[65] Hayley Peterson. 2018. Missing wages, grueling shifts, and bottles of urine: The disturbing accounts of Amazon delivery drivers may reveal the true human cost of 'free' shipping. Business Insider (11 Sep 2018). https://www. businessinsider.com/amazon-

delivery-drivers-reveal-claims-of-disturbingwork-conditions-2018-8 Accessed June 28, 2019.

[66] James Pierce. 2012. Undesigning Technology: Considering the Negation of Design by Design. In Proceedings of the SIGCHI Conference on Human Factors in Computing Systems (CHI '12). ACM, New York, NY, USA, 957-966. DOI :

http://dx.doi.org/10.1145/2207676.2208540

[67] Kamila Pope. 2017. Understanding Planned Obsolescence: unsustainability through production, consumption and waste generation. Kogan Page Publishers.

[68] Annu Sible Prabhakar. 2018. Designing for Compassion Cultivation. In Extended Abstracts of the 2018 CHI Conference on Human Factors in Computing Systems (CHI EA '18). ACM, New York, NY, USA, Article DC17, 4 pages. DOI : http://dx.doi.org/10.1145/3170427.3173035

[69] John Pruitt and Jonathan Grudin. 2003. Personas: Practice and Theory. In Proceedings of the 2003 conference on Designing for user experiences - DUX '03. ACM Press, New York, New York, USA, 1. DOI : http://dx.doi.org/10.1145/997078.997089

[70] Reddit. 2019. ToastMe. (2019). https://www.reddit. com/r/toastme/ Accessed: 2019-12-31. 
[71] Reuters. 2013. Young adults say technology can be dehumanizing - poll. (2013).

https://ca.news . yahoo. com/young-adultstechnology-dehumanizing-poll-122045068.html Accessed: 2019-08-09.

[72] Leon F. Seltzer. 2011. Why We Hide Emotional Pain. (2011). https:

//www.psychologytoday.com/us/blog/evolutionthe-self/201109/why-we-hide-emotional-pain Accessed: 2019-08-09.

[73] Emily Esfahani Smith. 2013. There's More to Life Than Being Happy. (2013). https : //www. theatlantic. com/ health/archive/2013/01/theres-more-to-lifethan-being-happy/266805/ Accessed: 2019-08-06.

[74] Robert Soden, Michael Skirpan, Casey Fiesler, Zahra Ashktorab, Eric P. S. Baumer, Mark Blythe, and Jasmine Jones. 2019. CHI4EVIL: Creative Speculation on the Negative Impacts of $\mathrm{HCl}$ Research. In Extended Abstracts of the $2019 \mathrm{CHI}$ Conference on Human Factors in Computing Systems (CHI EA '19). ACM, New York, NY, USA, Article W29, 8 pages. DOI: http://dx.doi.org/10.1145/3290607.3299033

[75] Reem Talhouk, Konstantin Aal, Anne Weibert, Max Krüger, Volker Wulf, Karen Fisher, Franziska Tachtler, Suleman Shahid, Syed Ishtiaque Ahmed, and Ana Maria Bustamante Duarte. 2019. Refugees \& HCl SIG: Situating HCI Within Humanitarian Research. In Extended Abstracts of the $2019 \mathrm{CHI}$ Conference on Human Factors in Computing Systems (CHI EA '19). Association for Computing Machinery, New York, NY, USA, Article Paper SIG14, 4 pages. DOI : http://dx.doi.org/10.1145/3290607.3311754

[76] James Temperton. 2016. Gorillas are being killed and eaten by miners in the Congo. (2016). https://www.wired.co.uk/article/grauersgorillas-bushmeat-conflict-minerals-technology Accessed: 2019-08-09.

[77] Amanda Haertling Thein, Richard Beach, and Daryl Parks. 2007. Perspective-Taking as Transformative Practice in Teaching Multicultural Literature to White Students. The English Journal 97, 2 (2007), 54-60. http://www.jstor.org/stable/30046789

[78] Bill Tomlinson. 2010. Greening through IT. MIT Press.

[79] Bill Tomlinson, M. Six Silberman, Donald Patterson, Yue Pan, and Eli Blevis. 2012. Collapse Informatics: Augmenting the Sustainability \& ICT4D Discourse in $\mathrm{HCl}$. In Proceedings of the SIGCHI Conference on Human Factors in Computing Systems (CHI '12). ACM, New York, NY, USA, 655-664. DOI : http://dx.doi.org/10.1145/2207676.2207770

[80] UN. 2017. Female Empowerment Would Unleash Potential to Chart New Global Future, Secretary-General Tells Commission on Status of Women | Meetings Coverage and Press Releases. (2017). https:

//www.un.org/press/en/2017/wom2106. doc.htm

[81] USDA. 2019. Livestock Slaughter. (2019). https://usda.library.cornell.edu/concern/ publications/rx913p88g?locale=en Accessed: 2019-09-16.

[82] Tatiana A. Vlahovic, Yi-Chia Wang, Robert E. Kraut, and John M. Levine. 2014. Support Matching and Satisfaction in an Online Breast Cancer Support Community. In Proceedings of the 32nd Annual ACM Conference on Human Factors in Computing Systems (CHI '14). ACM, New York, NY, USA, 1625-1634. DOI: http://dx.doi.org/10.1145/2556288.2557108 
[83] Duncan J. Watts. 2003. Small Worlds: The Dynamics of Networks Between Order and Randomness. Princeton University Press, Princeton, NJ, USA.

[84] Tyler W. Watts, Greg J. Duncan, and Haonan Quan. 2018. Revisiting the Marshmallow Test: A Conceptual Replication Investigating Links Between Early Delay of Gratification and Later Outcomes. Psychological Science 29, 7 (jul 2018), 1159-1177. DOI : http://dx.doi.org/10.1177/0956797618761661

[85] Euphemia Wong. 2019. Shneiderman's Eight Golden Rules Will Help You Design Better Interfaces. https://www.interaction-design.org/literature/ article/shneiderman-s-eight-golden-rules-willhelp-you-design-better-interfaces. (2019). Accessed: 2019-08-07.

[86] World Bank. 2018a. Climate Change Could Force Over 140 Million to Migrate Within Countries by 2050: World Bank Report. (2018).

https://www. worldbank.org/en/news/pressrelease/2018/03/19/climate-change-could-forceover-140-million-to-migrate-within-countriesby-2050-world-bank-report Accessed: 2019-08-09.

[87] World Bank. 2018b. Decline of Global Extreme Poverty Continues but Has Slowed: World Bank. (2018). https://www. worldbank. org/en/news/pressrelease/2018/09/19/decline-of-global-extremepoverty-continues-but-has-slowed-world-bank Accessed: 2019-08-09.

[88] World Health Organization. 2017. Depression and Other Common Mental Disorders Global Health Estimates. (2017)

https://apps.who.int/iris/bitstream/handle/ 10665/254610/WHO-MSD-MER-2017.2-eng.pdf;
jsessionid=502642CE03A3CE31E583A09C48DFA26F? sequence=1 Accessed: 2019-08-09.

[89] World Health Organization. 2018. Depression. (2018). https://www. who. int/news-room/factsheets/detail/depression Accessed: 2019-08-09.

[90] World Wildlife Fund. 2018. Living Planet Report 2018: Aiming Higher. (2018).

https://www.wwf .org.uk/sites/default/files/ 2018-10/LPR2018_Ful1\%20Report.pdf Accessed: 2019-08-09.

[91] World Wildlife Fund. 2019a. Dairy | Industries | WWF. (2019).

https://www.worldwildlife.org/industries/dairy Accessed: 2019-08-09.

[92] World Wildlife Fund. 2019b. How many species are we losing? (2019). http://wwf . panda.org/our_work/ biodiversity/biodiversity/ Accessed: 2019-08-09.

[93] Darrell A. Worthy, A. Ross Otto, and W. Todd Maddox. 2012. Working-memory load and temporal myopia in dynamic decision making. Journal of Experimental Psychology: Learning, Memory, and Cognition 38, 6 (2012), 1640-1658. DOI : http://dx.doi.org/10.1037/a0028146

[94] Peter Wright and John McCarthy. 2008. Empathy and Experience in $\mathrm{HCl}$. In Proceedings of the SIGCHI Conference on Human Factors in Computing Systems (CHI '08). ACM, New York, NY, USA, 637-646. DOI : http://dx.doi.org/10.1145/1357054.1357156

[95] Yuan Yang. 2017. Apple's iPhone X assembled by illegal student labour. (2017). https://www .ft . com/content/7cb56786-cda1-11e7b781-794ce08b24dc Accessed: 2019-08-09. 


\section{Commentary}

For alt.chi paper

Suffering-Centered Design

\section{Julieta Aguilera}

Independent Researcher

1129 Ferdinand Ave.

Forest Park, IL USA

julietina@me.com
Suffering-Centered Design advocates making the case for $\mathrm{HCI}$ to enhance human experience by opening to the suffering of others. Whereas the automatic response to the suffering of others is to ignore it, authors point out that HCI should not reinforce this stance as it results in more suffering and less solutions. They also cite examples of such problematic avoidances:

- Ignoring consequences even if they imply one's own suffering and other living creatures,

- Considering one's actions insignificant, and

- Undervaluing of life or prioritization of one's life above that of others.

Whereas suffering exist in real life and may result in action, interfaces may allow for users to hide what causes suffering in them. Applications may also overwhelm attention to decrease the saliency of suffering or put the user above others, even abstracting suffering to the point it is not perceived as such. On the other hand interfaces may help enhance the perceiving of suffering of others with increased connectivity, enabling contact among diverse communities. The authors propose a set of principles to work against the tendency to ignore suffering:

- Promoting exposure to a broader community,

- Changing the approach to suffering so it is not seen as a pathology but instead a call for action,

- Encouraging change of perspective, and

- Opposing unsustainable growth which results in suffering.
Suffering as a call for action is relevant as an aspect of interaction and there is research that expands on this topic, i.e., to acknowledge one's own state of awareness including suffering (Davidson, R. J. (2005). Emotion regulation, happiness, and the neuroplasticity of the brain), confront suffering through Mindfulness Based Stress Reduction -MBSR- (Mehling, et al., 2018. "A 12-week integrative exercise program improves self-reported mindfulness and interoceptive awareness in war veterans with posttraumatic stress symptoms"), research which has also utilized Virtual Reality to visit places where trauma took place, and finally research on behavior that pays attention to the suffering of others (Chierchia, Gabriele, and Tania Singer. "The neuroscience of compassion and empathy and their link to prosocial motivation and behavior").

In my own design and scientific visualization research I have noted that scaling perspective is not straight forward ("Point of View When Designing Around Behavior," 2019). In the larger Universe the conditions that affect phenomena outcomes change in relevance depending on scale. If not focused, human suffering may result in suprematism, for example by applying one's personal context to a whole community where one is in or to other communities without acknowledging the different circumstances of other individuals or groups in other contexts. Inter species suprematism may assume that animals will be happy if one does a nice human thing to them, placing the human umwelt over their own. Perhaps suffering, in changing its impact across scales and context, relates to attentional and emotional states that are more mindful of what drives interaction in the first place. 